\title{
Invited review: MicroRNAs in bovine colostrum-Focus on their origin and potential health benefits for the calf
}

\author{
I. Van Hese, ${ }^{1,2 *}$ K. Goossens, ${ }^{1}$ L. Vandaele, ${ }^{1}$ and G. Opsomer ${ }^{2}$ \\ ${ }^{1}$ Animal Sciences Unit, Flanders Research Institute for Agriculture, Fisheries and Food (ILVO), Scheldeweg, Melle, 9090, Belgium \\ ${ }^{2}$ Department of Reproduction, Obstetrics and Herd Health Faculty of Veterinary Medicine, Ghent University, Salisburylaan, Merelbeke, \\ 9820, Belgium
}

\section{ABSTRACT}

Colostrum is the first milk produced by a cow after she gives birth. Compared with mature milk, it has a high concentration of immunoglobulin G. Calves are born without circulating antibodies, thus ingestion of colostrum is necessary to protect the calf against pathogens in the first challenging weeks of life. In addition to the life-saving supply of antibodies, colostrum contains minerals, vitamins, growth factors, and immune cells. Recently, microRNAs (miRNAs) were added to that list. MicroRNAs are short, non-coding RNA molecules that can regulate gene expression at the post-transcriptional level. They are thought to act as key regulators of diverse biological and developmental processes. Colostrum contains higher amounts of miRNAs than mature milk; immune- and development-related miRNAs are prominent. Their expression pattern in milk is likely to be influenced by maternal nutrition and environment. The fat content of the maternal diet appears to have a major effect on expression of miRNAs in milk and in the neonate. The immunological state of the mammary gland seems to affect miRNA expression as well. In cows diagnosed with subclinical mastitis, alterations in the expression of miRNAs in milk have been observed. It is believed that miRNAs in colostrum and milk are signaling molecules passed from mother to newborn. They are packaged in extracellular vesicles, which makes them resistant to the harsh conditions in the gastrointestinal tract. Therefore, they can reach the small intestine, where they are absorbed and transferred into the bloodstream. MicroRNAs are important for the development of the intestines. For example, miRNAs stimulate cell viability, proliferation, and stem cell activity of the intestinal epithelium. Furthermore, miRNAs seem to act as key players in the development of the complete immune system. They can, among other

Received May 20, 2019.

Accepted September 6, 2019.

*Corresponding author: Ilke.VanHese@ilvo.vlaanderen.be things, regulate B- and T-cell differentiation and affect interleukin production of macrophages. The abundance of miRNAs in colostrum and milk and the possibility for their absorption in the intestines of the neonate supports the hypothesis that these tiny molecules are important for the development of the newborn. The probable relation of diet to the expression of miRNAs by the mother creates a possible avenue to optimize expression of miRNAs and improve neonatal maturation. Key words: colostrum, microRNA, neonatal development, dairy cow

\section{INTRODUCTION}

Calves are born agammaglobulinemic, meaning that they lack circulating antibodies. Their acquired immune system is completely present at birth but is not yet operational (Chase et al., 2008). In the first weeks of life, the neonate's ability to fight off pathogens is therefore fully dependent upon ingesting colostrum. Colostrum is the first milk that a female mammal produces after giving birth. In cows, colostrum contains a large portion of $\operatorname{IgG}$, which is absorbed in the calf's intestines and transported to the bloodstream to protect the calf from pathogens (Chase et al., 2008). This transfer of passive immunity is crucial for the calf's survival in the first challenging weeks of life. Absorption efficiency of $\mathrm{IgG}$ is highest during the first hours of life and ends approximately $24 \mathrm{~h}$ after birth ("gut closure"; Lora et al., 2018). Calves unable to absorb enough antibodies from colostrum have a higher risk of morbidity or death at a young age (1.91 and 2.12 times more likely, respectively; Raboisson et al., 2016).

Modern farmers are becoming more aware of the importance of fostering the health of newborn and young cattle to breed high-yielding dairy cows. Early life development can even determine the lifetime performance as a lactating dairy cow (Soberon et al., 2012).

In addition to transmitting antibodies, colostrum provides many other important nutrients and bioactive components, such as fat, protein, hormones, growth 
factors, vitamins, and minerals (Kehoe et al., 2007). Recently, microRNAs (miRNAs) have been added to that list (Chen et al., 2010).

MicroRNAs are short, noncoding RNA molecules of approximately 21 to 25 nucleotides (nt; Lau et al., 2001). In 1993, Lee et al. discovered that the lin-4 gene in Caenorhabditis elegans encoded a small RNA molecule that seemed to regulate translation of the lin-14 mRNA (Lee et al., 1993). It took almost $7 \mathrm{yr}$ until the next gene that encodes a short RNA transcript, let-7, was discovered, again in the nematode $C$. elegans (Reinhart et al., 2000). One year later, these novel short RNA molecules were categorized in a new class and thereafter referred to as miRNAs (Lagos-Quintana et al., 2001). Today, more than 38,000 precursor miRNAs, expressing almost 49,000 mature miRNAs have been discovered in 271 species (miRBase, release 22; Kozomara and Griffiths-Jones, 2011).

This review focuses on the bovine species and discusses the miRNA expression pattern in colostrum with possible effects on the calf after miRNA ingestion. Management factors that can alter miRNA expression patterns in colostrum are also presented.

\section{MICRORNA EXPRESSION IN COLOSTRUM AND MILK: AN EVOLUTIONARY ADVANTAGE FOR MAMMALS?}

The mammalian species arose more than 200 million years ago and can be distinguished from other species by the development of a mammary gland that produces milk as part of the reproductive strategy (Lefèvre et al., 2010). Besides its nutritional value, milk has a distinct function in delivering biochemical signals to the neonate. These maternal regulators (e.g., miRNAs), direct the newborn's growth and development (Power and Schulkin, 2013).

MicroRNAs are, in general, highly conserved between different species. For example, the let- 7 family is detected in arthropods, nematodes, fish, birds, and mammals (Lee et al., 2007). In other words, at some point throughout evolution, post-transcriptional regulation by miRNAs became indispensable. However, similarities in miRNA sequences between different species does not mean they share the same function. In arthropods, let-7 plays a role in the transition from larval to adult stage, whereas in mammals, the let-7 family contains more members and are involved in neural differentiation, limb development, and oncogenesis in the lung (Lee et al., 2007). As the structural complexity of organisms increases, so too does the number of novel miRNAs detected. It is thought that this increase in miRNAs is the basis for the formation of new tissues and organs throughout evolution (Lee et al., 2007). This implies that a more complex expression of miRNAs contributed to the evolution of a mammary gland and lactation. MicroRNAs therefore have 2 functions: (1) the miRNAs expressed in mammary gland tissue are related to the functionality of the mammary gland itself; and (2) recent discoveries of circulating miRNAs in mammals in several body fluids, including colostrum and milk (Chen et al., 2010; Weber et al., 2010), indicate that these miRNAs play a key role in the communication between mother and offspring. This could mean that they are valuable for neonatal development.

\section{MICRORNA EXPRESSION PATTERNS IN THE MAMMARY GLAND}

The miRNA first discovered in C. elegans, lin-4, plays a key role in the development from larval to adult stage, and its expression is stage-specific. At the end of the first larval stage, expression is activated. The lin-4 gene is a negative regulator of the LIN-14 protein: an increase in lin-4 induces a decrease in LIN-14 protein, which seems to be a crucial step in the development from larvae to adult (Lee et al., 1993). When we apply this knowledge to development of lactation in the cow, we can hypothesize that miRNAs could contribute to the regulation of this process. Moreover, by understanding miRNA expression patterns in the mammary gland during lactation, we might gain insight into the origin, regulation, and function of miRNAs expressed in colostrum and milk.

In the study of Li et al. (2012b), the miRNA expression profile of mammary gland tissue originating from a cow in lactation (2 mo postpartum) was compared with mammary gland tissue of a nonlactating, nonpregnant cow. Of the 544 miRNAs detected in both libraries, only 56 were differentially expressed (DE) between the lactation and nonlactation period (Table 1). For example, the expression of miR-141, which downregulates the translation of signal transducer and activator of transcription 5 (STAT5) protein, is reduced in the mammary gland during lactation (Li et al., 2012b). The STAT5 protein is crucial for alveolar development in the mammary gland and subsequently for lactogenesis (Liu et al., 1997). Therefore, it is likely that miR-141 plays a role in the regulation of lactation. In another study, 13 miRNAs associated with cellular proliferation, lipid metabolism, and innate immunity were selected to perform a real-time reverse-transcription PCR on bovine mammary gland tissue from different lactational stages (dry period, fresh period, and early lactation; Wang et al., 2012). All but one of the miRNAs (miR-31) seemed to be downregulated in the dry period compared with during lactation (Table 1; Wang et al., 2012). Because of the small subset of miRNAs analyzed, these results 
Table 1. Comparison of differentially expressed (DE) microRNAs (miRNAs) in mammary gland tissue during different lactation stages

\begin{tabular}{|c|c|c|c|c|c|}
\hline Sample period & Species & $\begin{array}{l}\text { Detection } \\
\text { method }^{1}\end{array}$ & $\begin{array}{l}\text { DE miRNAs/ } \\
\text { total detected }\end{array}$ & $\begin{array}{l}\text { Upregulated miRNAs }{ }^{2} \text { in mammary } \\
\text { gland tissue }\end{array}$ & Reference \\
\hline $\begin{array}{l}\text { Dry period vs. } \\
\text { lactation }\end{array}$ & Bovine & RT-qPCR & $13 / 13$ & $\begin{array}{l}\text { In lactation: miR-10a, miR-15b, miR-16, miR- } \\
\text { 21, miR-31, miR-33b, miR-145, miR-146b, } \\
\text { miR-155, miR-181a, miR-205, miR-221, and } \\
\text { miR-223 }\end{array}$ & Wang et al. (2012) \\
\hline $\begin{array}{c}\text { Nonlactation } \\
\text { vs. lactation }\end{array}$ & Bovine & NGS & $56 / 544$ & $\begin{array}{l}\text { In non-lactation: miR-10a, miR-146b, miR- } \\
205 \text {, miR-221 } \\
\text { In lactation: miR-33b }\end{array}$ & Li et al. (2012b) \\
\hline $\begin{array}{l}\text { Transition vs. } \\
\text { peak lactation }\end{array}$ & Caprine & NGS & $131 / 568$ & $\begin{array}{l}\text { In transition period: miR-15b, miR-21, miR- } \\
155, \text { miR-221, miR-223 }\end{array}$ & Hou et al. (2017) \\
\hline $\begin{array}{l}\text { Dry period vs. } \\
\text { lactation }\end{array}$ & Caprine & NGS & $169 / 294$ & $\begin{array}{l}\text { In dry period: miR-15b, miR-16, miR-21, } \\
\text { miR-31, miR-145, miR-181a, miR-205, miR- } \\
\text { 221, and miR-223 }\end{array}$ & Li et al. (2012a) \\
\hline
\end{tabular}

${ }^{1} \mathrm{RT}$-qPCR $=$ reverse transcription quantitative PCR; NGS = next-generation sequencing.

${ }^{2}$ Solely DE miRNAs from the 13 miRNAs selected by Wang et al. (2012) are represented.

cannot confirm an overall downregulation of miRNAs in the dry period. Lactation-related differential expression of miRNAs seems to be present in other ruminants as well. In the dairy goat, 169 miRNAs were differentially expressed, with 165 downregulated and 4 upregulated miRNAs during peak lactation (75 d postpartum) compared with the dry period ( $\mathrm{Li}$ et al., 2012a). A total of 131 miRNAs were identified as differentially expressed with 45 upregulated and 86 downregulated miRNAs in the transition ( $2 \mathrm{~d}$ postpartum) versus peak lactation (90 d postpartum; Hou et al., 2017). The transition is the period between colostrum and mature milk production and lasts for approximately $5 \mathrm{~d}$. In this period, colostrum gradually changes into milk as the protein (mainly immunoglobulins) and fat contents decrease (Sánchez-Macías et al., 2014).

Several miRNAs that show a higher expression in dairy goat mammary glands during mid lactation (120 d postpartum) compared with early lactation (30 d postpartum) were linked to milk fat synthesis in the mammary gland (Lin et al., 2013). Moreover, expression of these particular miRNAs seemed to be upregulated with a higher concentration of prolactin, a hormone that regulates lactation (Lin et al., 2013). Overall, it is plausible that miRNAs play a part in regulating lactation and that their expression is related to different stages of lactation. However, it remains unclear how miRNA expression in the mammary gland is regulated and which mechanism underlies the differential temporal expression. Study results show some important contradictions. For example, miR-10a, miR-146b, miR-205, and miR-221 were upregulated in lactational mammary gland tissue in the study of Wang et al. (2012), whereas Li et al. (2012b) reported upregulation of these miRNAs in nonlactational mammary gland tissue (Table 1). The reason for this is unclear; a difference in the animal's management's history (e.g., environment, nutrition) or differences in RNA isolation and detection methods used have been suggested (Izumi et al., 2012). Another explanation could be interspecies dissimilarities (Silveri et al., 2006; Wang et al., 2012). This could explain the difference in miRNA expression between the caprine and bovine mammary gland, which is plausible because even miRNA expression in the mammary gland between 2 cattle breeds differs. Comparison of miRNA expression in the mammary gland between Holstein-Friesian and Limousin heifers showed differential expression of 54 miRNAs, and the majority of these miRNAs were upregulated in Limousin heifers (Wicik et al., 2016). The miRNAs that differed most between the 2 breeds seemed to inhibit genes related to metabolic processes and signaling pathways that are important in stem cell activity and the development of the mammary gland (Wicik et al., 2016). This was explained by the more advanced development of the mammary gland of dairy cows compared with beef cows (Wicik et al., 2016), with the result that these genes are less inhibited. However, the sample size in that study was low-only 4 animals per group were sampled. Moreover, samples were collected at the slaughterhouse, which means that no background information (e.g., management, nutrition, treatment, lactation stage) of the animals was available. Further studies are needed to confirm DE of miRNAs between different cattle breeds and the implications of this DE.

We can conclude that miRNAs play an important role in the development of the mammary gland and that miRNA expression is stage-dependent. How- 
ever, functionality of the miRNAs and the underlying mechanism between miRNA expression and mammary gland development and lactation stages must be further investigated.

\section{MICRORNA EXPRESSION PATTERNS IN COLOSTRUM AND MILK}

\section{Differential Expression Between Colostrum and Milk}

Over the past few years, miRNAs present in bovine colostrum and mature milk samples have been identified using next-generation sequencing (Chen et al., 2010) and microarray analysis (Izumi et al., 2012; see Table 2). Chen et al. (2010) detected 230 and 213 known miRNAs in colostrum and milk respectively, with 198 miRNAs present in both. Colostrum and milk were collected from 80 cows at $7 \mathrm{~d}$ and 9 mo postpartum, respectively. Izumi et al. (2012) detected 100 known miRNAs in colostrum and 53 in milk, with 51 miRNAs common to both. They sampled 5 cows within $3 \mathrm{~d}$ postpartum for colostrum and 5 cows from $8 \mathrm{~d}$ to $8 \mathrm{mo}$ in lactation for mature milk. One explanation for the differing results between these 2 studies could be the different sampling volumes. Chen et al. (2010) extracted RNA from $100 \mathrm{~mL}$ of pooled colostrum and mature milk, whereas Izumi et al. (2012) used only 2.5 to 6.5 $\mathrm{mL}$ of individual colostrum and milk samples to extract RNA. Furthermore, Chen et al. (2010) performed an additional PAGE purification of small RNA molecules, enabling them to detect very small quantities of miRNAs (Izumi et al., 2012). Another important difference is the sampling time of colostrum. The most striking difference between colostrum and milk is the concentration of antibodies, especially $\operatorname{IgG}_{1}$ (Barrington et al., 2001). There is some disagreement in literature about the duration of colostrum secretion by the cow. Some study results state that colostrum production stops immediately after giving birth, whereas others claim that it lasts for $7 \mathrm{~d}$ (McGrath et al., 2016). The generally agreed upon definition is that colostrum is the milk produced in the first $3 \mathrm{~d}$ after parturition (McGrath et al., 2016). Whether a difference in miRNA expression could exist in this first $7 \mathrm{~d}$ of lactation has not been investigated. Also important to note is that the sample groups used in the study of Izumi et al. (2012) lacked standardization, as colostrum samples were derived almost exclusively from heifers, whereas, for mature milk, exclusively multiparous cows were sampled. Whether this could influence the results is unclear because, so far, an effect of parity on miRNA expression has not been studied.

Several studies demonstrated a higher miRNA concentration in bovine milk at the beginning of the lacta- tion ( 1 to $7 \mathrm{~d}$ ) compared with mid lactation (2 to 4 mo; Hata et al., 2010; Izumi et al., 2012) or late lactation (6 to 9 mo; Chen et al., 2010; Izumi et al., 2012; Sun et al., 2013). In porcine breast milk exosomes, miRNA expression profiles clustered together for colostrum samples (taken at 0 and $3 \mathrm{~d}$ of lactation) and for mature milk (taken at 7, 14, 21, and 28 d of lactation; $\mathrm{Gu}$ et al., 2012). This difference in expression between colostrum and milk is intriguing, although the reason for it remains unclear. We can hypothesize that it is related to the needs of the neonate, but this requires further study. Whether secretion of miRNAs in milk and colostrum is of importance to the cow is not clear. MicroRNAs are thought to regulate the immune system of the cow, which is summarized in the review of Lawless et al. (2014b). In human and mouse research, it has been shown that miRNAs are key players in regulating the immune response; however, similar research has yet to be conducted in bovine research (Lawless et al., 2014b). Furthermore, deep research is needed to find a link between miRNAs secreted in colostrum and milk and the medical history or immunity of the cow herself.

\section{Origin of miRNAs Expressed in Colostrum and Milk}

Because of the different miRNA expression profiles between plasma and milk in several mammalian species, the contribution of the maternal circulation to miRNAs expressed in milk is presumably limited (Kosaka et al., 2010; Izumi et al., 2014; Modepalli et al., 2014; Alsaweed et al., 2016). The presence in milk-derived microvesicles of several miRNAs that are expressed in mammary gland tissue has been confirmed (Hata et al., 2010). The study of Li et al. (2012a) showed that the top 20 most abundant miRNAs in the dairy goat mammary gland and the top 20 most abundant miRNAs in raw milk had 13 common members (let-7a, let-7b, let-7c, let-7f, let-7g, miR-21, miR-230a, miR2103, miR-2107, miR-2143, miR-2148a, miR-2320, and miR-2423-5p). When the miRNA expression profiles of different bovine milk fractions (fat, whey, and cells) were compared with that of mammary gland tissue, the miRNome of the milk fat fraction was most similar to that of the mammary gland, followed by whey. This is in contrast with the cell fraction, which had the fewest similarities (Li et al., 2016). Therefore, endogenous synthesis in the lactating mammary epithelium is thought to be the main source of miRNAs in milk (Li et al., 2012a; Modepalli et al., 2014; Alsaweed et al., 2016). Most of the extracellular miRNAs appear to be released passively, although there is some evidence of selective release of miRNAs by cells (Pigati et al., 2010; Li et al., 2012a). This process is likely cell-type specific, yet the 
Van Hese et al.: INVITED REVIEW: MICRORNAS IN BOVINE COLOSTRUM

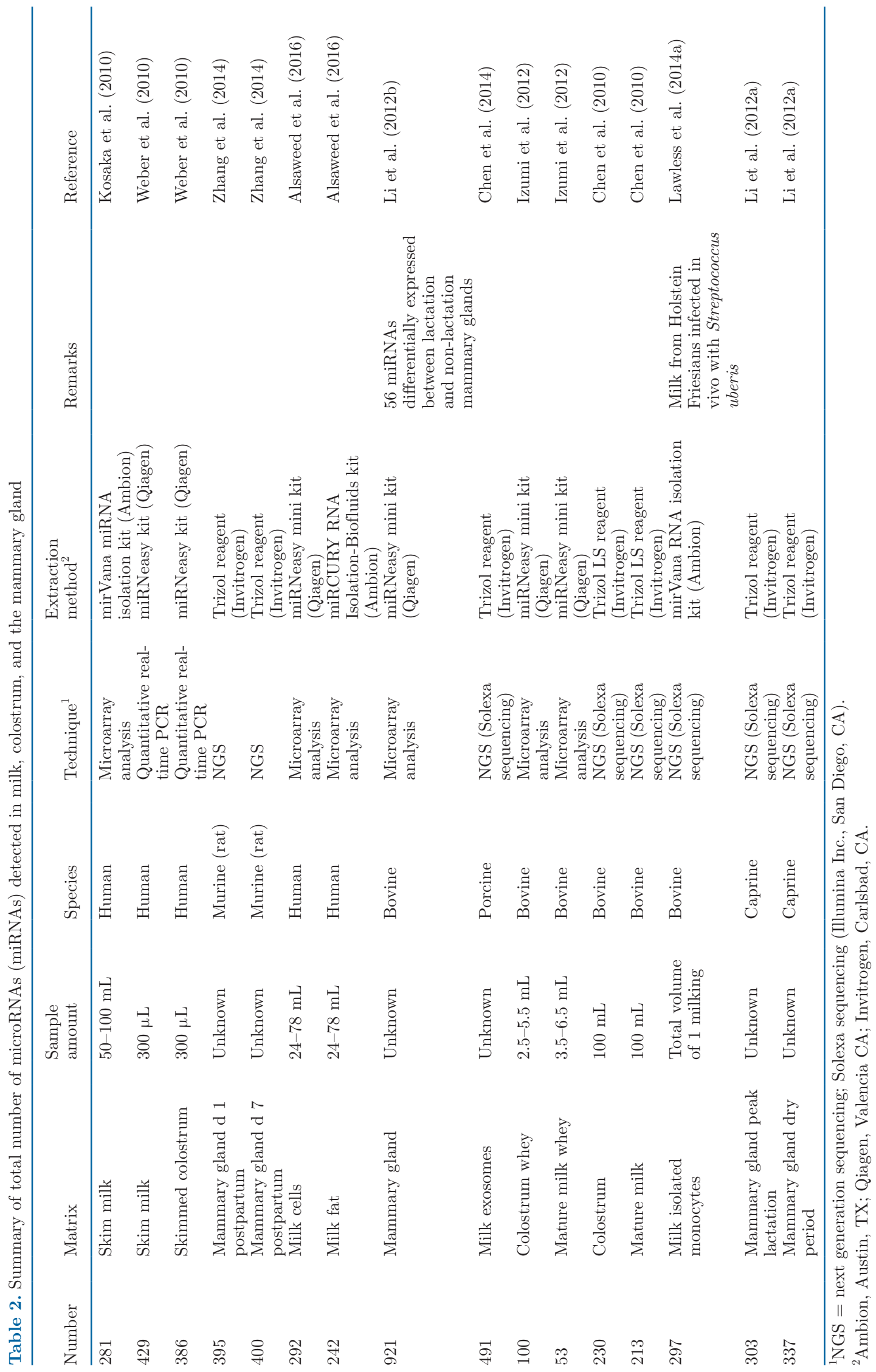


mechanism behind selective release of miRNAs remains unclear (Pigati et al., 2010).

\section{MiRNAs in Colostrum and Milk Are Packaged in Exosomes}

Milk-derived miRNAs, in contrast to mRNA and cellular miRNAs, are stable under harsh conditions: they are resistant to RNase treatment, an acidic environment, (Hata et al., 2010; Kosaka et al., 2010; Gu et al., 2012; Izumi et al., 2012; Modepalli et al., 2014), and freeze-thaw cycles (Kosaka et al., 2010; Gu et al., 2012; Muth et al., 2018). This suggests that miRNAs can survive the environment of the neonate's gastrointestinal tract (GIT) and can, as such, be absorbed in the intestines (Kosaka et al., 2010; Gu et al., 2012; Izumi et al., 2012). Kirchner et al. (2016) studied the effect of heat treatment of bovine milk on the survival of miRNAs expressed in milk. Ultra-high heat treatment (preheating: $23 \mathrm{~s}$ at $95^{\circ} \mathrm{C}$; direct steam injection: $5 \mathrm{~s}$ at $142^{\circ} \mathrm{C}$ ), extended shelf-life treatment (preheating: $20 \mathrm{~s}$ at $90^{\circ} \mathrm{C}$; direct steam injection: $5 \mathrm{~s}$ at $127^{\circ} \mathrm{C}$ ) and boiling (preheating: $>300 \mathrm{~s}$ at $>80^{\circ} \mathrm{C}$; boiling: $30 \mathrm{~s}$ at $100^{\circ} \mathrm{C}$ ) led to substantial degradation of miRNAs. Pasteurization $\left(20 \mathrm{~s}\right.$ at $\left.72^{\circ} \mathrm{C}\right)$, on the other hand, showed no reduction in miRNA levels (Kirchner et al., 2016). The above-mentioned techniques are used for treatment of bovine milk for human consumption. Pasteurization is also used by farmers to lower the bacterial load of colostrum. It is advised to heat colostrum for 30 to 60 min at $60^{\circ} \mathrm{C}$. This technique uses a lower temperature than commercial milk treatment to avoid degradation of colostral IgG (Elizondo-Salazar et al., 2010). In this regard, it is possible that pasteurization of colostrum does not affect miRNA concentration. However, the effect of the duration of heating colostrum on the miRNA concentration is not fully clear yet and should be further investigated. In the study of Benmoussa et al. (2016), commercially available dairy milk was used to test the survival rate of miRNAs in the GIT. To mimic the digestion of a healthy adult, they used the TNO computer-controlled in vitro gastrointestinal model, TIM-1, which is composed of 4 connected compartments that mimic the environment of the stomach, duodenum, jejunum, and ileum, respectively. Benmoussa et al. (2016) showed that a high amount of milk-derived miRNAs withstood these conditions and that miRNAs reached the small intestine (the main location for absorption of nutrients). Therefore, it is likely that miRNAs may be functional in the GIT of neonates after ingestion of milk (Izumi et al., 2014). A potential explanation for the high survival rate of miRNAs under these conditions is their storage in cell-derived membrane vesicles such as microvesicles or exosomes (see Figure 1; Hata et al., 2010; Kosaka et al., 2010; Gu et al., 2012; Izumi et al., 2012; Modepalli et al., 2014; Wolf et al., 2015; Alsaweed et al., 2016; Benmoussa et al., 2016; Rani et al., 2017).

In the literature, the terminology of these cell-derived membrane vesicles can lead to confusion because different nomenclature is used (Mathivanan et al., 2010). The term "microvesicles" is often used to refer to a mixed population of vesicles, including exosomes, shedding microvesicles, and apoptotic bodies (Mathivanan et al., 2010), although in many reports, "microvesicle" is specially used to describe a vesicle shed directly from the plasma membrane (Figure 1; van Dommelen et al., 2012). Exosomes are nanosized (40-100 nm diameter) vesicles with a phospholipid bilayer that originate from the endosomal system and are released to the extracellular environment through multivesicular bodies after budding with the plasma membrane (van Dommelen et al., 2012). Chen et al. (2014) demonstrated that exosomes isolated from porcine milk contained 176 known and 315 novel mature miRNAs. This phenomenon was also seen in bovine colostrum and milk (Hata et al., 2010). In addition, in human as well as in bovine milk, miRNAs can also be transported within milk fat globules (Munch et al., 2013; Alsaweed et al., 2016; Li et al., 2016). Milk fat globules are synthesized and released by mammary epithelial cells and contain mainly triacylglycerols (Heid and Keenan, 2005). Because the secretion of milk fat globules marks a complete surrounding of the plasma membrane before the globule is split off from the cell, these globules could be seen as a specific form of shedding vesicles (see Figure 1; Heid and Keenan, 2005). In the process of milk fat globule secretion, miRNAs present in the cytoplasm of mammary epithelial cells can be enclosed by these fat globules before being released into the milk (Li et al., 2016). Furthermore, an association between miRNAs and large protein complexes is also suggested (Modepalli et al., 2014). Extracellular miRNAs are found to be associated with argonaute RISC catalytic component 2 (AGO2), a protein that plays a central role in the RNA-induced silencing complex (RISC) in plasma and cell culture medium (Turchinovich et al., 2011). It is thought that these AGO2/miRNA complexes are by-products of cell death and are highly stable in the extracellular space (Turchinovich et al., 2011).

\section{Influences on Expression Pattern in Milk and Colostrum}

Could external factors such as nutrition, environment, or health of the dam alter the miRNA expression in milk? After noting a large variation in miRNA expression between individuals, Kosaka et al. (2010) has 
suggested nutritional and environmental influences on the expression patterns of miRNA in milk.

Nutrition. As we already know, nutrition has an important influence on milk composition in dairy cows, with milk fat composition being very sensitive to dietary changes (Sutton, 1989). Since Boussingault and Lebel discovered that nutrition affects milk composition (Playfair, 1841), a great deal of research in ration formulation has been conducted. After the discovery of miRNAs in colostrum and milk, some researchers are shifting their focus toward the effect of nutrition on miRNA composition in milk, but the connections remain tenuous. Research in women and mice has already clearly revealed the effect of the diet on miRNA expression in milk and in offspring (Zhang et al., 2009; Munch et al., 2013; Benatti et al., 2014).

It seems that a high-fat diet can influence the expression pattern of miRNA in human milk. Women who consume a diet rich in fat $(30 \%$ carbohydrate, $55 \%$ fat, and $15 \%$ protein) showed increased expression of miR-67 and miR-27 in their milk fat globules compared with women on an high-carbohydrate diet (60\% carbohydrate, $25 \%$ fat, and $15 \%$ protein; Munch et al., 2013). Mice that received a diet rich in fat (5.24 $\mathrm{kcal} / \mathrm{g}$ ), showed $25 \mathrm{DE}$ miRNAs compared with mice fed a control diet (3.85 kcal/g; Chen et al., 2017). When cows were fed a diet supplemented with $5 \%$ safflower or linseed oil, 22 and 14 miRNAs (7 in common), respec-

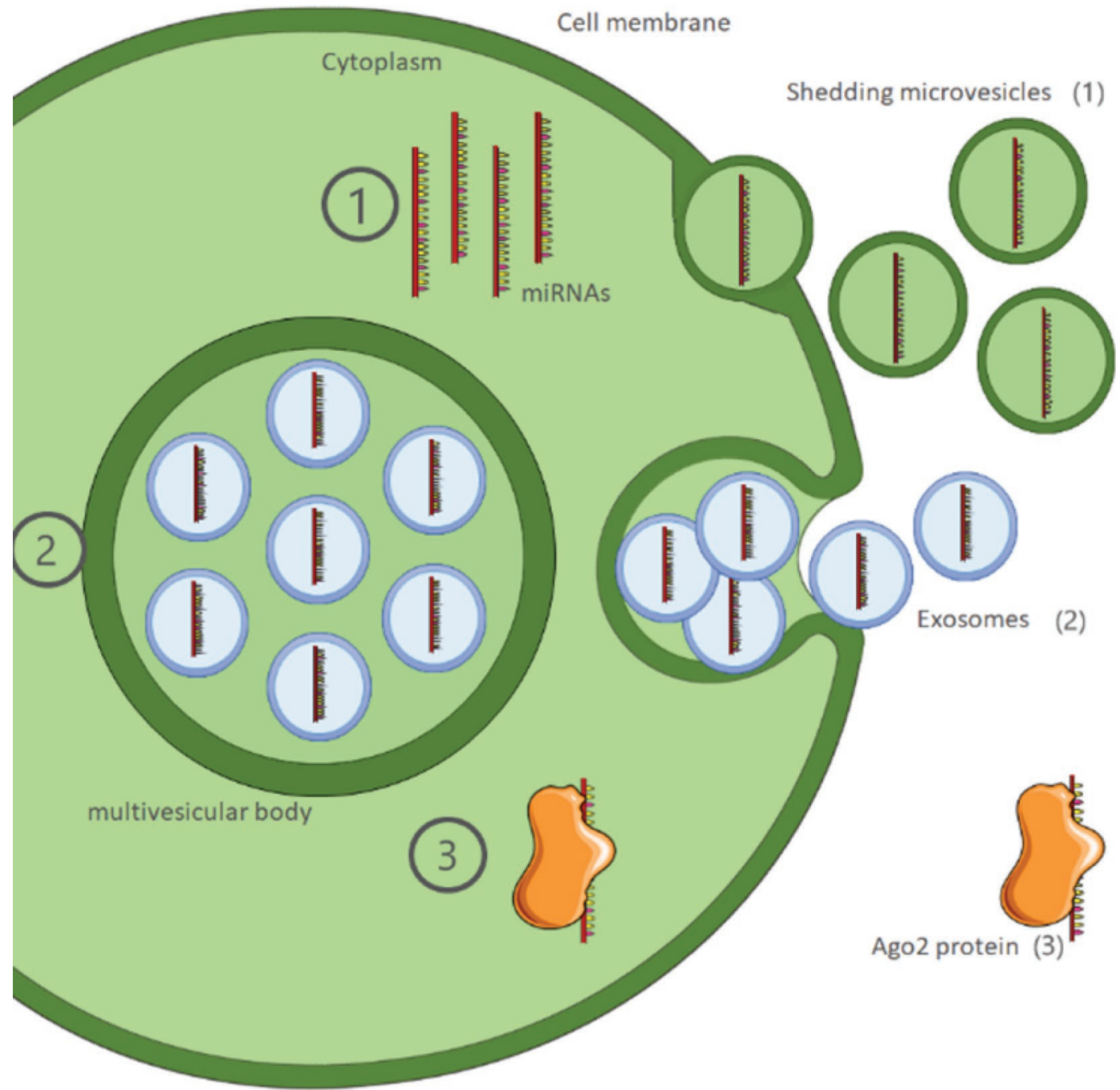

Figure 1. Common mechanisms for extracellular appearance of microRNAs (miRNAs): they can be stored in shedding microvesicles (1), exosomes (2) or associated with Argonaute 2 (AGO2) protein (3). (C) 2013 Hessvik, Sandvik and Llorente. Adapted from Hessvik et al. (2013). This figure was created using Servier Medical Art templates (https://smart.servier.com), licensed under a Creative Commons Attribution 3.0 Unported License. 
tively, were differentially expressed in the mammary gland (Li et al., 2015). The 7 DE miRNAs common to both treatments were associated with gene targets related to lipid metabolism (Li et al., 2015). Whether these DE miRNAs could affect the offspring's metabolism is not clear. Besides an alteration in miRNA expression, supplementation with safflower or linseed oil caused a reduction in milk fat (Li et al., 2015). There seems to be a connection between maternal nutrition during lactation and miRNA expression in the milk, especially for fat content of the diet. Although the crude protein level of the maternal diet during late gestation affects IgG absorption in calves (Quigley and Drewry, 1998), the effect of maternal protein supply on miRNA expression in colostrum has yet to be determined.

Furthermore, it seems that maternal diet during pregnancy and lactation can affect miRNA expression in the offspring (Zhang et al., 2009). When female mice were fed a high-fat diet (22.6\% fat, $23 \%$ protein and $48.6 \%$ carbohydrate) during pregnancy and lactation, an increase of 10 and a decrease of 23 miRNAs were detected in liver tissue of the offspring compared with that in dams fed a standard chow diet (10\% fat, $68.8 \%$ carbohydrate, and $18 \%$ protein; Zhang et al., 2009). Benatti et al. (2014) used the same approach and reported that feeding female mice with a high-fat diet during gestation and lactation led to up- and downregulation of miR-370 and miR-122, respectively, in the liver of offspring. The reduction in miR-122 and increase in miR-370 in liver were associated with changes in the oxidative pathway (Benatti et al., 2014). It is possible that these differences in expression already find their origin in the uterus and are maintained during suckling. This is only an assumption, however, as the effect on miRNA expression was not studied if pups from standard chow mothers would suckle mothers on the high-fat diet and vice versa. Further research is warranted to reveal whether a similar effect of maternal dietary changes occurs in dairy calves. As with expression patterns in the milk, no link has been found so far between protein content of the maternal diet during gestation and miRNA expression in the offspring (Liu et al., 2011; Cong et al., 2012; Jacometo et al., 2018).

Infection. In extensive production systems with highly productive dairy cows, mastitis is the most common production-related condition (Seegers et al., 2003). This disease can have a distinct effect on the physiology of the mammary gland and the production results of the cow (Seegers et al., 2003). Therefore, it is likely that this disease could affect the expression of miRNA in the mammary gland and consequently in both colostrum and milk.

When the bovine mammary gland was challenged with a Staphylococcus aureus infection, 6 miRNAs were significantly differentially expressed in milk exosomes, miR-142-5p, miR-223, miR-183, and miR-99a-5p were upregulated, and miR-2285g-3p and miR-101 were downregulated (Sun et al., 2015). In vitro experiments with cultured bovine mammary epithelial cells revealed changes in miRNA expression after inoculation with Streptococcus uberis. MicroRNA expression was measured at 4 time points (1, 2, 4, and $6 \mathrm{~h}$ after infection) and 21 miRNAs seemed to be differentially expressed. Fifteen miRNAs were upregulated and 7 miRNAs were downregulated, with one miRNA (miR-29e) being upregulated $2 \mathrm{~h}$ after infection and downregulated 6 h after infection (Lawless et al., 2013). Furthermore, monocytes isolated from milk showed differential expression of 26 miRNAs after in vivo inoculation of the mammary gland with Strep. uberis (Lawless et al., 2014a). It is hypothesized that differentially expressed miRNAs after bacterial infection could regulate immune response in the mammary gland (Lawless et al., 2013, 2014a; Sun et al., 2015). Moreover, it is thought that miRNAs that target genes associated with the immune response are downregulated after a bacterial infection, meaning that suppression of these genes by miRNAs is less pronounced (Lawless et al., 2014a). This research in miRNA expression during bacterial IMI has great potential to find noninvasive biomarkers for early detection of subclinical mastitis (Lawless et al., 2014a; Sun et al., 2015). MicroRNAs have become very popular in human medicine as biomarkers for early detection of several diseases, such as breast cancer for example (Etheridge et al., 2011). Given the high prevalence of mastitis in dairy cattle, it would be interesting to dig deeper into its effect on milk miRNA expression and, more importantly, to develop better diagnostic tools in the early detection of this disease. Moreover, it is possible that altered miRNA expression due to mastitis affects neonatal development. Although highly discouraged, many farmers still administer waste milk from cows with mastitis to their calves (Vasseur et al., 2010). In this regard, better knowledge on implications for the calf of feeding mastitic milk and the DE of miRNAs due to mastitis is needed.

\section{MiRNAs in Colostrum and Milk: Potential Implications for the Neonate}

Neonates clearly ingest miRNAs via colostrum, but do those miRNAs remain biologically active after delivery in the gut? It could be that they either act (only) locally in the GIT or that they are absorbed in the intestines and delivered to other organs where they affect gene expression. However, these hypotheses require further study. Additionally, it is believed that insufficient uptake of dietary miRNAs cannot be compen- 
sated for by endogenous synthesis of miRNAs (Baier et al., 2014). When mice were fed miRNA-depleted milk, the plasma concentration of miR-29b decreased by $61 \%$ compared with mice fed miRNA-containing milk (Baier et al., 2014); miR-29b is associated with osteoblastogenesis - specifically, it targets inhibitors of osteoblast differentiation (Li et al., 2009). In addition to a decrease in miR-29b, a lower expression of Krüppel-like factor $8(K L F 8)$ mRNA was found in the liver of miRNA-depleted mice (Baier et al., 2014); KLF8 is a DNA-binding transcriptional regulator that contributes in different biological processes (Funnell et al., 2013). Whether KLF8 is regulated by miR-29b and what the biological relevance of this decrease might be were not reported. However, based on the predictions of TargetScanMouse (release 7.2; http://www.targetscan .org/mmu_72/), the repression of KLF8 by miR-29b seems rather low with a context++ score of -0.05 (Agarwal et al., 2015). This score is calculated as the sum of the contribution of 14 features for each of the 4 site types. Site type (e.g., 8mer) and the minimum distance of the site from the stop codon are 2 of the 14 features (Agarwal et al., 2015). The value range goes from 1 to -1 , and the more negative the score, the greater the repression (Riffo-Campos et al., 2016).

Transportation of miRNAs to the Neonate. The uptake of dietary delivered miRNAs has received increasing attention over the past few years (Hata et al., 2010; Zhang et al., 2012; Snow et al., 2013; Baier et al., 2014; Modepalli et al., 2014; Hirschi et al., 2015; Wolf et al., 2015; Rani et al., 2017). Although the presence of plant- and animal-specific miRNAs delivered through food to serum of human (Zhang et al., 2012) and animals (Zhang et al., 2012; Yang et al., 2015a,b) has been confirmed, it is thought that in certain diets, the concentration of absorbed miRNAs is often too low to exert a biological effect on the recipient (Snow et al., 2013). This could be due to degradation of the miRNAs in the GIT or because of a low supply via the diet (Snow et al., 2013). However, several questions remain - are these miRNAs even important nutrients? How is their absorption regulated? And which concentration is needed to be biologically active?

Mechanism Behind the Absorption of miRNAs in the GIT. We know that miRNAs are absorbed in the GIT and transferred to the bloodstream. What is the mechanism behind this absorption? As mentioned above, miRNAs in colostrum and milk are stored in exosomes. It is hypothesized that exosomes and microvesicles carry specific surface proteins that attach to the intestinal epithelium (Modepalli et al., 2014; Wolf et al., 2015). This suggests that the absorption of miRNAs through the intestinal wall is carried out by endocytosis, whereby exosomes and microvesicles release their contents into the epithelial cells (Wolf et al., 2015). The uptake of miRNAs has been seen in different types of cells. When murine embryonic fibroblasts (NIH-3T3 cells) were incubated with milkderived microvesicles, evidence of miRNA transfer was observed (Hata et al., 2010). This phenomenon was also seen when cultured macrophages were incubated with milk- and colostrum-derived microvesicles (Sun et al., 2013). In addition, in humans, an increase in miRNA concentration was seen in human peripheral blood mononuclear cells (PBMCs) after ingestion of cow milk (Baier et al., 2014). Moreover, the membrane structure of the microvesicles and exosomes seems to be crucial in the miRNA transfer to other cells (Sun et al., 2013). The overall number of miRNAs present in colostrum and milk are contained in cell-derived vesicles. This suggests that these miRNAs are meant to be absorbed in the GIT of the recipient. If true, this strengthens the hypothesis that they are an important and biologically meaningful nutrient for the neonate.

Concentration-Dependent Absorption of miRNAs. In contrast to the findings of Snow et al. (2013), where the absorption of miRNAs delivered through 3 different diets (vegetarian, soy-enriched, and casein and lard diet) was minimal, miRNAs delivered through milk consumption appear to be absorbed in meaningful amounts in the intestines. The study of Arntz et al. (2015) revealed an uptake of bovine milkderived extracellular vesicles (BMEV) in the ileum in in vitro experiments (Arntz et al., 2015). In an in vivo experiment, the absorption of 2 miRNAs, miR-29b and miR-200c, in humans after ingestion of bovine milk was investigated (Baier et al., 2014). Before consumption, the cow milk contained $148 \pm 42$ and $680 \pm 151 \mathrm{pmol} / \mathrm{L}$ of miR-29b and miR-200c, respectively. Plasma concentrations of miR-29b showed a linear dose-response relation with the amount of milk consumed $(0.25,0.5$, and $1 \mathrm{~L}$ ); plasma concentrations of miR-200c were also highest for the highest consumption amount, although this dose-response relation was not linear. The maximum serum concentration of miR-29b occurred 3.4 to $4.2 \mathrm{~h}$ after the ingestion of milk. Furthermore, the return to baseline concentrations of these miRNAs took more time with higher milk consumption, $9 \mathrm{~h}$ for 0.25 - and $0.5-\mathrm{L}$ doses and $24 \mathrm{~h}$ when $1 \mathrm{~L}$ of milk was consumed (Baier et al., 2014). These postprandial increases of miRNA levels in human serum could also be seen after the ingestion of chicken eggs (Zempleni et al., 2015). Besides being concentration-dependent, the absorption of food-delivered miRNAs seems to be miRNA-specific as well.

Newborns as well as adults are able to absorb miRNAs from their diet. In neonates, whose first diet consists mainly of maternal milk, an increase in serum 
miRNA concentrations was observed after ingestion of colostrum (Gu et al., 2012) and milk (Gu et al., 2012; Modepalli et al., 2014). In the study of Chen et al. (2016), an intracellular elevation of miRNAs was seen after the incubation of neonatal piglet-derived intestinal enterocytes (IPEC-J2) with milk exosomes. When miRNA absorption in piglets was compared following consumption of colostrum versus mature milk, 9 of 13 immune-related miRNAs showed significantly higher expression in the serum of piglets given only colostrum (Gu et al., 2012). Because these immune-related miRNAs are more highly expressed in colostrum than in mature milk (Gu et al., 2012), the higher absorption of these miRNAs in colostrum-fed piglets is likely concentration related.

Furthermore, uptake of miRNAs seems to be facilitated by prolonged and high dosage exposure (Hirschi et al., 2015). It is suggested that some dietary components could stimulate the uptake of miRNAs (Hirschi et al., 2015). For example, mice fed honeysuckle (Lonicera japonica) versus chow supplemented with a synthetic plant miRNA, miR-168a, showed higher serum levels of this miRNA (Yang et al., 2015b). In addition, miRNA absorption is related to the permeability of the intestinal epithelium. Alterations or damage to the gut are associated with higher absorption of dietary miRNAs (Yang et al., 2015b). Because the calf's gut is more permeable in the first $24 \mathrm{~h}$ of life (Lora et al., 2018), higher absorption of miRNAs in this short period can be presumed. This hypothesis requires thorough investigation.

\section{Biological Effect of miRNAs Delivered to the Neonate}

Intestines. MicroRNAs seem to be important in the differentiation and functional development of the intestinal epithelium. McKenna et al. (2010) used knockout mice deficient in the gene encoding Dicer 1, an enzyme crucial for activity of the miRNA (Figure 2 ). The mutant miRNA-deficient mice were smaller than control littermates in early life, probably because of the less-efficient digestion of fat molecules present in milk (the feces of mutant mice contained large fat droplets when they were fed a fat-rich diet; McKenna et al., 2010). The intestinal epithelium of mutant mice was completely disorganized, with an increase in lymphocyte infiltration, a severe increase in apoptosis of epithelial cells, and decreased function of the intestinal epithelial barrier (McKenna et al., 2010). This suggests that miRNAs are crucial for the normal morphology and function of the intestines. Moreover, it is likely that miRNAs present in colostrum and milk are important for intestinal development. Chen et al. (2014) suggested that miRNAs present in porcine milk exosomes play a role in the development of the digestive tract. In an in vivo experiment in mice, daily administration of porcine milk exosomes significantly promoted villus height and crypt depth of the duodenum and jejunum (Chen et al., 2016). This effect is probably induced by RNA molecules, which stimulate expression of several transcription and proliferation factors (CDX2, proliferating cell nuclear antigen, and IGF-1R) in the jejunum and reduce expression of protein p53 (Chen et al., 2016), an important regulator of cell death (Kruiswijk et al., 2015). Exosomes present in rat milk are also associated with a beneficial effect on intestinal development. It is suggested that they stimulate cell viability, proliferation, and stem cell activity of the intestinal epithelium (Hock et al., 2017).

In the study of Liang et al. (2014), temporal and regional differences in miRNA expression profiles of the GIT in dairy calves were investigated from birth to 42 $\mathrm{d}$ of age (samples taken at $0,7,21$, or $42 \mathrm{~d}$ of age). The small intestines showed the largest temporal change in miRNA expression during the first week of life, which can be linked to the rapid development of the intestines in this period (Liang et al., 2014). One of the factor related to the temporal alterations of miRNA expression patterns is dietary change (Liang et al., 2014). Colostrum and, to a lesser extent, mature milk contain relevant amounts of development-related miRNAs (Izumi et al., 2012). Moreover, the 10 highest-expressed miRNAs in the calf's intestines are represented in colostrum and milk, with 6 of them (miR-192, miR-194, miR-143, miR-378, miR-10a, and miR-181a) being upregulated in colostrum (Chen et al., 2010; Liang et al., 2014). These findings could signify the contribution of colostrum and milk feeding in the temporal changes of miRNA expression, as well as in the development of the intestines. However, it remains unknown what concentration of miRNAs in milk or colostrum is needed to exert a biological effect in the recipient, in this case the calf. When adult humans consumed $1 \mathrm{~L}$ of milk containing $148 \pm 42$ and $680 \pm 151 \mathrm{pmol} / \mathrm{L}$ of miR-29b and miR-200c, respectively, their plasma concentrations of miR-29b increased from $232 \pm 51$ to $624 \pm 83$ $\mathrm{fmol} / \mathrm{L}$ and that of miR-200c increased from $458 \pm 37$ to $924 \pm 121 \mathrm{fmol} / \mathrm{L}$ (Baier et al., 2014). These maximal plasma concentrations were measured $3.6 \pm 0.6 \mathrm{~h}$ after consumption (Baier et al., 2014). Gene expression in human PBMCs of the RUNX2 gene was elevated by $31 \pm 13 \%$ after milk consumption (Baier et al., 2014). MicroRNA-29b is a positive regulator of the RUNX2 gene ( $\mathrm{Li}$ et al., 2009), which could explain these findings. Thus, bovine milk contains certain miRNAs that exert a biological effect in the recipient. However, similar studies are lacking in dairy calves. Further research is needed to confirm the hypothesis that colostrum and 
milk contain miRNAs that are biologically available in the calf. In addition to the dietary influence, the density of bacteria (mainly Bifidobacterium and Lactobacillus spp.) present in the GIT is correlated with the expression of miRNAs (Liang et al., 2014). This again highlights the complexity of the contribution of miRNAs in the organism's physiology and metabolism.

Immunology. MicroRNAs can affect many cell types and regulate numerous target genes from close range or at a distance (Chen et al., 2012). Hata et al. (2010) pointed out the presence of immune-related miRNAs in bovine milk-derived microvesicles. Moreover, immunerelated miRNAs seemed to be upregulated in colostrum compared with mature milk in cows (Izumi et al., 2012; Sun et al., 2013) and pigs (Gu et al., 2012). This phenomenon was first seen in human breast milk, where these miRNAs are upregulated during the first $6 \mathrm{mo}$ of lactation (Kosaka et al., 2010). In Li et al. (2012a), 4 of the top 20 most abundant miRNAs (miR-29a, miR-230a, miR-2101, and miR-2146b) in the mammary gland of dairy goats are immune-related miRNAs. The expression levels of these miRNAs were similar between the mammary gland and the milk (Li et al., 2012a). We can hypothesize that the higher levels of immunerelated miRNAs are correlated with the needs of the neonate, especially in the early stages of life when their immune system still needs to mature.

MicroRNAs are believed to participate in the development and regulation of the immune system (Xiao and Rajewsky, 2009; O'Connell et al., 2010; Chen et al., 2014; Alsaweed et al., 2015, 2016). This effect is thought to act through alterations in gene expression of several immune cells, such as T and B cells, monocytes, macrophages, neutrophils, and dendritic cells (Kosaka

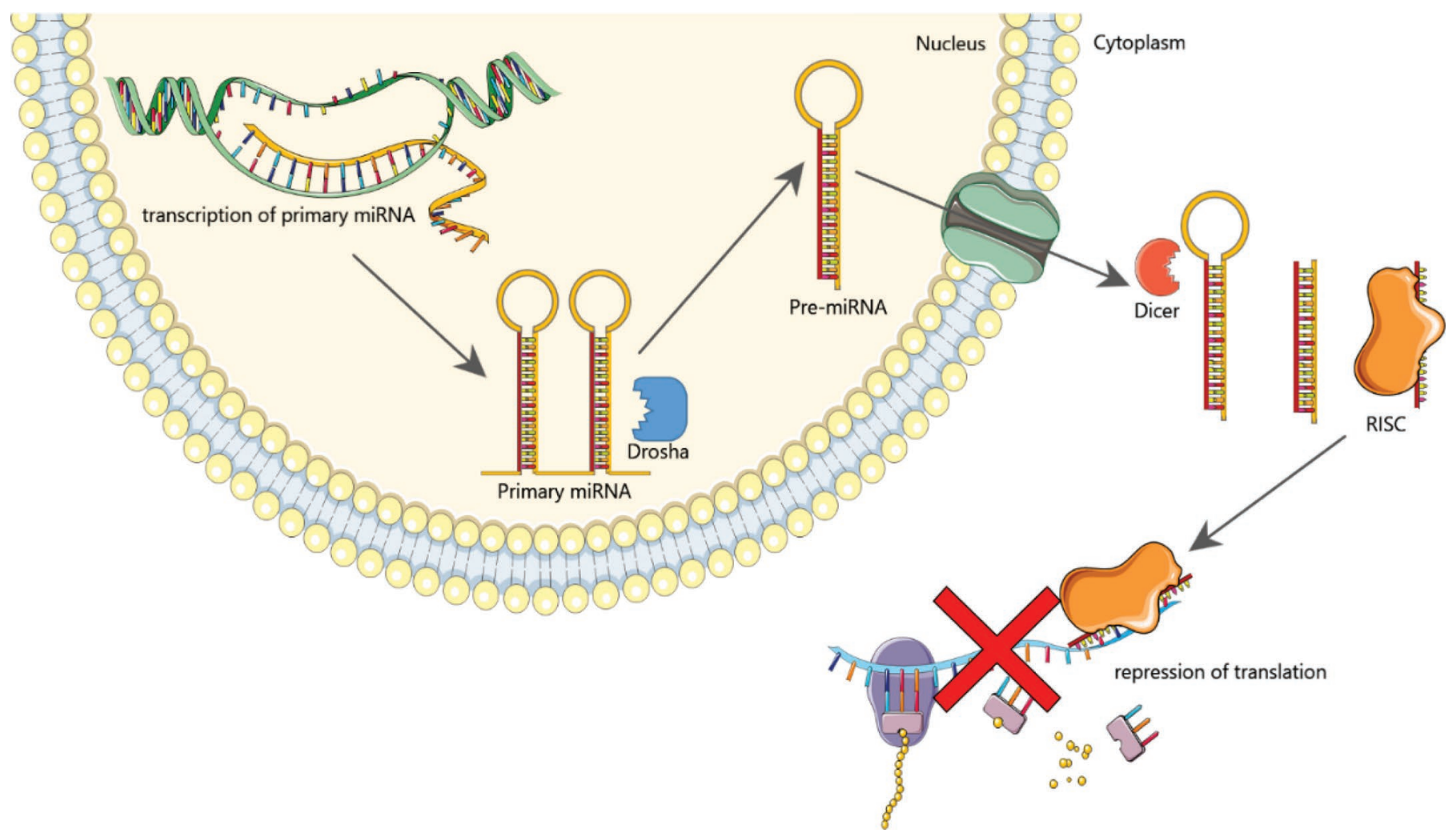

Figure 2. Genes coding for miRNAs are transcribed by RNA polymerase II (RNA pol II) or RNA pol III into a primary miRNA (primiRNA) transcript (Lee et al., 2004; Borchert et al., 2006). The pri-miRNAs are long and are cleaved in the nucleus by Drosha, an RNase III ribonuclease, into an approximately 60- to 70-nt precursor hairpin, better known as the pre-miRNA (Lee et al., 2002, 2003). The pre-miRNA is actively transported by exportin-5 to the cytoplasm, where it is processed into a 20-bp miRNA/miRNA* duplex by another RNase III ribonuclease, called Dicer (Lee et al., 2002; Yi et al., 2003; Krol et al., 2010), where the asterisk denotes the strand of the duplex that will be degraded as the other one will be loaded into the RNA-induced silencing complex (RISC). Eventually, 1 of the 2 miRNA strands is loaded into the RISC, the other strand will be degraded (Lodish et al., 2008). In mammals, RISC is composed by the mature miRNA and the Argonaute 2 protein (AGO2) (Liu et al., 2004). This complex will bind to a corresponding mRNA, which will lead to degradation or repression of the translation of the mRNA (Lodish et al., 2008). The main purpose is to reduce the production of targeted proteins. This is why miRNAs are called regulators of gene expression at a post-transcriptional level (Lodish et al., 2008). This figure was created using Servier Medical Art templates (https:// smart.servier.com), licensed under a Creative Commons Attribution 3.0 Unported License. Adapted by permission from Springer Nature: Nature Reviews Immunology, Micromanagement of the immune system by microRNAs. H. F. Lodish, B. Zhou, G. Liu, and C. Z. Chen. ${ }^{\circ} 2008$. 
et al., 2010; Alsaweed et al., 2015; Arntz et al., 2015). It is suggested that milk miRNAs play an important role in the maturation of the neonate's immune system (Izumi et al., 2014). For example, miR-181 and miR155 are both regulators of B- and T-cell differentiation and are abundant in human breast milk (Kosaka et al., 2010). Arntz et al. (2015) showed that bovine-milk derived microvesicles can have an anti-inflammatory function and may suppress the adaptive immune response. Moreover, colostrum-derived vesicles play a regulating role in cytokine production (Sun et al., 2013). When cultured macrophages were challenged with LPS after exposure to colostrum vesicles, IL- 1 and IL-6 production increased IL-10 production decreased; however, this effect was only seen when the macrophages were challenged with a low concentration of LPS (Sun et al., 2013). In addition, if colostrum-derived vesicles would exert a positive effect on phagocytosis in incubated macrophages, this effect would be higher than with milk-derived vesicles (Sun et al., 2013).

The most abundant miRNAs in porcine milk exosomes are thought to be involved in the IgA immune network and may target several immune-related genes (Chen et al., 2014). The let- 7 miRNA family members, for example, are assumed to affect IgA production in the digestive tract of the piglet (Chen et al., 2014). When isolated murine splenocytes were incubated with BMEV, a reduction in the LPS-induced tumor necrosis factor $\alpha(\mathrm{TNF}-\alpha)$ and monocyte chemoattractant protein 1 (MCP-1) production could be seen (Arntz et al., 2015). Furthermore, BMEV seemed to exert a therapeutic effect when they were orally administered to mice suffering from autoimmune arthritis (Arntz et al., 2015). Additionally, Liang et al. (2014) suggest that miRNAs are involved in development of the mucosal immune system in the small intestine.

All these findings suggest that maternal signaling through miRNAs may be important in the development of the newborn and that they contribute to a variety of biological processes. Still, literature on this matter is relatively sparse, especially in bovine research. Previous research focused mainly on the importance of miRNA expression in milk for human consumption. Studies on the effect of miRNA delivery through colostrum and milk ingestion in neonatal calves are still rare. Moreover, it should be acknowledged that current studies on miRNA expression in bovine colostrum deviated from the true definition of colostrum and sampled transition milk. Colostrum is the first milk a cow produces after giving birth, and the transition to mature milk takes approximately $5 \mathrm{~d}$. Future research on the miRNA expression in colostrum of first milking would be more interesting as this is the neonate's very first meal. In addition, more research should be done on the possible absorption of miRNAs in the neonate's gut; if these miRNAs are absorbed, then possible biological effects should be investigated.

\section{CONCLUSIONS}

Milk and especially colostrum are complex fluids that contain essential nutrients for the newborn. Colostrum and milk are the neonate's first source of nutrition and are therefore crucial for development and growth. There is evidence that miRNAs are abundant in both colostrum and milk. They are stored in exosomes, which makes it possible to survive in the GIT. In the small intestines, miRNAs can be absorbed and transferred to the bloodstream. Because endogenous synthesis cannot compensate for dietary deficiencies of certain miRNAs, the supply of miRNAs through feed intake could be more important than initially thought. There are indications that these colostrum- and milkdelivered miRNAs exert an effect on the recipient. They can act locally in the intestines or be transported via the bloodstream to affect biological processes in other parts of the body, such as the immune system. The abundance of miRNAs in colostrum and milk and the alteration of their expression during these lactational stages indicate that this pattern follows the neonate's needs. For example, immune-related miRNAs are expressed more in colostrum than in mature milk, which might be related to the immature immune system of the newborn calf. However, true links between these findings are still missing. If the presence of miRNAs in colostrum were important for the development of the newborn calf, it would be interesting to study whether the expression could be altered due to management factors, such as nutrition. So far, dietary effects on the miRNA expression patterns in bovine milk have not received very much attention. In general, studies on the effect of ration composition on expression of miRNAs are scarce. The few studies that are published on this matter report an effect of dietary fat content in humans and mice. However, further research is needed to determine ways to optimize miRNA expression through maternal nutrition. Overall, we conclude that miRNAs present in colostrum and milk represent a mechanism of postnatal signaling from the mother to the neonate. They are important regulators in the development of the newborn that can influence different biological processes. Future research should focus on the underlying mechanisms of expression in colostrum and milk and the effects on the (neonatal) recipient. 


\section{ACKNOWLEDGMENTS}

Ilke Van Hese is an SB PhD fellow at Fonds voor Wetenschappelijk Onderzoek-Vlaanderen (FWO, Research Foundation, Flanders), under project number $1 \mathrm{~S} 20218 \mathrm{~N}$.

\section{REFERENCES}

Agarwal, V., G. W. Bell, J. W. Nam, and D. P. Bartel. 2015. Predicting effective microRNA target sites in mammalian mRNAs. eLife 4:e05005. https://doi.org/10.7554/eLife.05005.

Alsaweed, M., P. E. Hartmann, D. T. Geddes, and F. Kakulas. 2015. MicroRNAs in breastmilk and the lactating breast: Potential immunoprotectors and developmental regulators for the infant and the mother. Int. J. Environ. Res. Public Health 12:13981-14020. https://doi.org/10.3390/ijerph121113981.

Alsaweed, M., C. T. Lai, P. E. Hartmann, D. T. Geddes, and F. Kakulas. 2016. Human milk miRNAs primarily originate from the mammary gland resulting in unique miRNA profiles of fractionated milk. Sci. Rep. 6:20680. https://doi.org/10.1038/srep20680.

Arntz, O. J., B. C. Pieters, M. C. Oliveira, M. G. Broeren, M. B. Bennink, M. de Vries, P. L. van Lent, M. I. Koenders, W. B. van den Berg, P. M. van der Kraan, and F. A. van de Loo. 2015. Oral administration of bovine milk derived extracellular vesicles attenuates arthritis in two mouse models. Mol. Nutr. Food Res. 59:1701-1712. https://doi.org/10.1002/mnfr.201500222.

Baier, S. R., C. Nguyen, F. Xie, J. R. Wood, and J. Zempleni. 2014. MicroRNAs are absorbed in biologically meaningful amounts from nutritionally relevant doses of cow milk and affect gene expression in peripheral blood mononuclear cells, HEK-293 kidney cell cultures, and mouse livers. J. Nutr. 144:1495-1500. https://doi.org/ 10.3945/jn.114.196436.

Barrington, G. M., T. B. McFadden, M. T. Huyler, and T. E. Besser. 2001. Regulation of colostrogenesis in cattle. Livest. Prod. Sci. 70:95-104. https://doi.org/10.1016/S0301-6226(01)00201-9.

Benatti, R. O., A. M. Melo, F. O. Borges, L. M. Ignacio-Souza, L. A. Simino, M. Milanski, L. A. Velloso, M. A. Torsoni, and A. S. Torsoni. 2014. Maternal high-fat diet consumption modulates hepatic lipid metabolism and microRNA-122 (miR-122) and microRNA-370 (miR-370) expression in offspring. Br. J. Nutr. 111:21122122. https://doi.org/10.1017/S0007114514000579.

Benmoussa, A., C. H. Lee, B. Laffont, P. Savard, J. Laugier, E. Boilard, C. Gilbert, I. Fliss, and P. Provost. 2016. Commercial dairy cow milk microRNAs resist digestion under simulated gastrointestinal tract conditions. J. Nutr. 146:2206-2215. https://doi.org/10 $.3945 /$ jn.116.237651.

Borchert, G. M., W. Lanier, and B. L. Davidson. 2006. RNA polymerase III transcribes human microRNAs. Nat. Struct. Mol. Biol. 13:1097-1101. https://doi.org/10.1038/nsmb1167.

Chase, C. C., D. J. Hurley, and A. J. Reber. 2008. Neonatal immune development in the calf and its impact on vaccine response. Vet. Clin. North Am. Food Anim. Pract. 24:87-104. https://doi.org/10 .1016/j.cvfa.2007.11.001.

Chen, T., Q. Y. Xi, R. S. Ye, X. Cheng, Q. E. Qi, S. B. Wang, G. Shu, L. N. Wang, X. T. Zhu, Q. Y. Jiang, and Y. L. Zhang. 2014. Exploration of microRNAs in porcine milk exosomes. BMC Genomics 15:100. https://doi.org/10.1186/1471-2164-15-100.

Chen, T., M. Y. Xie, J. J. Sun, R. S. Ye, X. Cheng, R. P. Sun, L. M. Wei, M. Li, D. L. Lin, Q. Y. Jiang, Q. Y. Xi, and Y. L. Zhang. 2016. Porcine milk-derived exosomes promote proliferation of intestinal epithelial cells. Sci. Rep. 6:33862. https://doi.org/10 $.1038 /$ srep33862.

Chen, X., C. Gao, H. Li, L. Huang, Q. Sun, Y. Dong, C. Tian, S. Gao, H. Dong, D. Guan, X. Hu, S. Zhao, L. Li, L. Zhu, Q. Yan, J. Zhang, K. Zen, and C. Y. Zhang. 2010. Identification and characterization of microRNAs in raw milk during different periods of lactation, commercial fluid, and powdered milk products. Cell Res. 20:1128-1137. https://doi.org/10.1038/cr.2010.80.
Chen, X., H. Liang, J. Zhang, K. Zen, and C. Y. Zhang. 2012. Secreted microRNAs: A new form of intercellular communication. Trends Cell Biol. 22:125-132. https://doi.org/10.1016/j.tcb.2011.12.001.

Chen, Y., J. Wang, S. Yang, S. Utturkar, J. Crodian, S. Cummings, J. Thimmapuram, P. San Miguel, S. Kuang, M. Gribskov, K. Plaut, and T. Casey. 2017. Effect of high-fat diet on secreted milk transcriptome in midlactation mice. Physiol. Genomics 49:747-762. https://doi.org/10.1152/physiolgenomics.00080.2017.

Cong, R., Y. Jia, R. Li, Y. Ni, X. Yang, Q. Sun, N. Parvizi, and R. Zhao. 2012. Maternal low-protein diet causes epigenetic deregulation of HMGCR and CYP7alpha1 in the liver of weaning piglets. J. Nutr. Biochem. 23:1647-1654. https://doi.org/10.1016/j.jnutbio .2011.11.007.

Elizondo-Salazar, J. A., B. M. Jayarao, and A. J. Heinrichs. 2010. Effect of heat treatment of bovine colostrum on bacterial counts, viscosity, and Immunoglobulin G concentration. J. Dairy Sci. 93:961-967. https://doi.org/10.3168/jds.2009-2388.

Etheridge, A., I. Lee, L. Hood, D. Galas, and K. Wang. 2011. Extracellular microRNA: A new source of biomarkers. Mutat. Res. 717:85-90. https://doi.org/10.1016/j.mrfmmm.2011.03.004.

Funnell, A. P., K. S. Mak, N. A. Twine, G. J. Pelka, L. J. Norton, T. Radziewic, M. Power, M. R. Wilkins, K. S. Bell-Anderson, S. T. Fraser, A. C. Perkins, P. P. Tam, R. C. Pearson, and M. Crossley. 2013. Generation of mice deficient in both KLF3/BKLF and KLF8 reveals a genetic interaction and a role for these factors in embryonic globin gene silencing. Mol. Cell. Biol. 33:2976-2987. https:// doi.org/10.1128/MCB.00074-13.

Gu, Y., M. Li, T. Wang, Y. Liang, Z. Zhong, X. Wang, Q. Zhou, L. Chen, Q. Lang, Z. He, X. Chen, J. Gong, X. Gao, X. Li, and X. Lv. 2012. Lactation-related microRNA expression profiles of porcine breast milk exosomes. PLoS One 7:e43691. https://doi.org/10 .1371/journal.pone.0043691.

Hata, T., K. Murakami, H. Nakatani, Y. Yamamoto, T. Matsuda, and N. Aoki. 2010. Isolation of bovine milk-derived microvesicles carrying mRNAs and microRNAs. Biochem. Biophys. Res. Commun. 396:528-533. https://doi.org/10.1016/j.bbrc.2010.04.135.

Heid, H. W., and T. W. Keenan. 2005. Intracellular origin and secretion of milk fat globules. Eur. J. Cell Biol. 84:245-258. https://doi .org/10.1016/j.ejcb.2004.12.002.

Hessvik, N. P., K. Sandvig, and A. Llorente. 2013. Exosomal miRNAs as biomarkers for prostate cancer. Front. Genet. 4:36. https://doi .org/10.3389/fgene.2013.00036.

Hirschi, K. D., G. J. Pruss, and V. Vance. 2015. Dietary delivery: A new avenue for microRNA therapeutics? Trends Biotechnol. 33:431-432. https://doi.org/10.1016/j.tibtech.2015.06.003.

Hock, A., H. Miyake, B. Li, C. Lee, L. Ermini, Y. Koike, Y. Chen, P. Maattanen, A. Zani, and A. Pierro. 2017. Breast milk-derived exosomes promote intestinal epithelial cell growth. J. Pediatr. Surg. 52:755-759. https://doi.org/10.1016/j.jpedsurg.2017.01.032.

Hou, J., X. An, Y. Song, B. Cao, H. Yang, Z. Zhang, W. Shen, and Y. Li. 2017. Detection and comparison of microRNAs in the caprine mammary gland tissues of colostrum and common milk stages. BMC Genet. 18:38. https://doi.org/10.1186/s12863-017-0498-2.

Izumi, H., N. Kosaka, T. Shimizu, K. Sekine, T. Ochiya, and M. Takase. 2012. Bovine milk contains microRNA and messenger RNA that are stable under degradative conditions. J. Dairy Sci. 95:4831-4841. https://doi.org/10.3168/jds.2012-5489.

Izumi, H., N. Kosaka, T. Shimizu, K. Sekine, T. Ochiya, and M. Takase. 2014. Time-dependent expression profiles of microRNAs and mRNAs in rat milk whey. PLoS One 9:e88843. https://doi.org/10 .1371/journal.pone.0088843.

Jacometo, C. B., A. S. Alharthi, Z. Zhou, D. Luchini, and J. J. Loor. 2018. Maternal supply of methionine during late pregnancy is associated with changes in immune function and abundance of microRNA and mRNA in Holstein calf polymorphonuclear leukocytes. J. Dairy Sci. 101:8146-8158. https://doi.org/10.3168/jds .2018-14428.

Kehoe, S. I., B. M. Jayarao, and A. J. Heinrichs. 2007. A survey of bovine colostrum composition and colostrum management practices on Pennsylvania dairy farms. J. Dairy Sci. 90:4108-4116. https:// doi.org/10.3168/jds.2007-0040. 
Kirchner, B., M. W. Pfaffl, J. Dumpler, E. von Mutius, and M. J. Ege. 2016. microRNA in native and processed cow's milk and its implication for the farm milk effect on asthma. J. Allergy Clin. Immunol. 137:1893-1895e13. https://doi.org/10.1016/j.jaci.2015.10.028.

Kosaka, N., H. Izumi, K. Sekine, and T. Ochiya. 2010. microRNA as a new immune-regulatory agent in breast milk. Silence 1:7. https:// doi.org/10.1186/1758-907X-1-7.

Kozomara, A., and S. Griffiths-Jones. 2011. miRBase: Integrating microRNA annotation and deep-sequencing data. Nucleic Acids Res. 39(Database):D152-D157. https://doi.org/10.1093/nar/gkq1027.

Krol, J., I. Loedige, and W. Filipowicz. 2010. The widespread regulation of microRNA biogenesis, function and decay. Nat. Rev. Genet. 11:597-610. https://doi.org/10.1038/nrg2843.

Kruiswijk, F., C. F. Labuschagne, and K. H. Vousden. 2015. p53 in survival, death and metabolic health: A lifeguard with a licence to kill. Nat. Rev. Mol. Cell Biol. 16:393-405. https://doi.org/10 $.1038 / \mathrm{nrm} 4007$.

Lagos-Quintana, M., R. Rauhut, W. Lendeckel, and T. Tuschl. 2001. Identification of novel genes coding for small expressed RNAs. Science 294:853-858. https://doi.org/10.1126/science.1064921.

Lau, N. C., L. P. Lim, E. G. Weinstein, and D. P. Bartel. 2001. An abundant class of tiny RNAs with probable regulatory roles in Caenorhabditis elegans. Science 294:858-862. https://doi.org/10 .1126 /science.1065062.

Lawless, N., A. B. Foroushani, M. S. McCabe, C. O'Farrelly, and D. J. Lynn. 2013. Next generation sequencing reveals the expression of a unique miRNA profile in response to a gram-positive bacterial infection. PLoS One 8:e57543. https://doi.org/10.1371/journal .pone.0057543.

Lawless, N., T. A. Reinhardt, K. Bryan, M. Baker, B. Pesch, D. Zimmerman, K. Zuelke, T. Sonstegard, C. O'Farrelly, J. D. Lippolis, and D. J. Lynn. 2014a. MicroRNA regulation of bovine monocyte inflammatory and metabolic networks in an in vivo infection model. G3 (Bethesda) 4:957-971. https://doi.org/10.1534/g3.113 .009936 .

Lawless, N., P. Vegh, C. O'Farrelly, and D. J. Lynn. 2014b. The role of microRNAs in bovine infection and immunity. Front. Immunol. 5:611. https://doi.org/10.3389/fimmu.2014.00611.

Lee, C. T., T. Risom, and W. M. Strauss. 2007. Evolutionary conservation of microRNA regulatory circuits: An examination of microRNA gene complexity and conserved microRNA-target interactions through metazoan phylogeny. DNA Cell Biol. 26:209-218. https://doi.org/10.1089/dna.2006.0545.

Lee, R. C., R. L. Feinbaum, and V. Ambros. 1993. The C. elegans heterochronic gene lin- 4 encodes small RNAs with antisense complementarity to lin-14. Cell 75:843-854. https://doi.org/10.1016/0092 -8674(93)90529-Y

Lee, Y., C. Ahn, J. Han, H. Choi, J. Kim, J. Yim, J. Lee, P. Provost, O. Radmark, S. Kim, and V. N. Kim. 2003. The nuclear RNase IIl Drosha initiates microRNA processing. Nature 425:415-419. https: //doi.org/10.1038/nature01957.

Lee, Y., K. Jeon, J. T. Lee, S. Kim, and V. N. Kim. 2002. MicroRNA maturation: Stepwise processing and subcellular localization. EMBO J. 21:4663-4670. https://doi.org/10.1093/emboj/cdf476.

Lee, Y., M. Kim, J. Han, K. H. Yeom, S. Lee, S. H. Baek, and V. N. Kim. 2004. MicroRNA genes are transcribed by RNA polymerase II. EMBO J. 23:4051-4060. https://doi.org/10.1038/sj.emboj .7600385

Lefèvre, C. M., J. A. Sharp, and K. R. Nicholas. 2010. Evolution of lactation: Ancient origin and extreme adaptations of the lactation system. Annu. Rev. Genomics Hum. Genet. 11:219-238. https:// doi.org/10.1146/annurev-genom-082509-141806.

Li, R., F. Beaudoin, A. A. Ammah, N. Bissonnette, C. Benchaar, X. Zhao, C. Lei, and E. M. Ibeagha-Awemu. 2015. Deep sequencing shows microRNA involvement in bovine mammary gland adaptation to diets supplemented with linseed oil or safflower oil. BMC Genomics 16:884. https://doi.org/10.1186/s12864-015-1965-7.

Li, R., P. L. Dudemaine, X. Zhao, C. Lei, and E. M. Ibeagha-Awemu. 2016. Comparative analysis of the miRNome of bovine milk fat, whey and cells. PLoS One 11:e0154129. https://doi.org/10.1371/ journal.pone.0154129.
Li, Z., M. Q. Hassan, M. Jafferji, R. I. Aqeilan, R. Garzon, C. M. Croce, A. J. van Wijnen, J. L. Stein, G. S. Stein, and J. B. Lian. 2009. Biological functions of miR-29b contribute to positive regulation of osteoblast differentiation. J. Biol. Chem. 284:15676-15684. https://doi.org/10.1074/jbc.M809787200.

Li, Z., X. Lan, W. Guo, J. Sun, Y. Huang, J. Wang, T. Huang, C. Lei, X. Fang, and H. Chen. 2012a. Comparative transcriptome profiling of dairy goat microRNAs from dry period and peak lactation mammary gland tissues. PLoS One 7:e52388. https://doi.org/10 .1371/journal.pone.0052388.

Li, Z., H. Liu, X. Jin, L. Lo, and J. Liu. 2012b. Expression profiles of microRNAs from lactating and non-lactating bovine mammary glands and identification of miRNA related to lactation. BMC Genomics 13:731. https://doi.org/10.1186/1471-2164-13-731.

Liang, G., N. Malmuthuge, T. B. McFadden, H. Bao, P. J. Griebel, P. Stothard, and L. L. Guan. 2014. Potential regulatory role of microRNAs in the development of bovine gastrointestinal tract during early life. PLoS One 9:e92592. https://doi.org/10.1371/ journal.pone.0092592.

Lin, X., J. Luo, L. Zhang, and J. Zhu. 2013. MicroRNAs synergistically regulate milk fat synthesis in mammary gland epithelial cells of dairy goats. Gene Expr. 16:1-13. https://doi.org/10.3727/ $105221613 X 13776146743262$.

Liu, J., M. A. Carmell, F. V. Rivas, C. G. Marsden, J. M. Thomson, J. J. Song, S. M. Hammond, L. Joshua-Tor, and G. J. Hannon. 2004. Argonaute2 is the catalytic engine of mammalian RNAi. Science 305:1437-1441. https://doi.org/10.1126/science.1102513.

Liu, X., J. Wang, R. Li, X. Yang, Q. Sun, E. Albrecht, and R. Zhao. 2011. Maternal dietary protein affects transcriptional regulation of myostatin gene distinctively at weaning and finishing stages in skeletal muscle of Meishan pigs. Epigenetics 6:899-907. https://doi .org/10.4161/epi.6.7.16005.

Liu, X., G. W. Robinson, K. U. Wagner, L. Garrett, A. WynshawBoris, and L. Hennighausen. 1997. Stat5a is mandatory for adult mammary gland development and lactogenesis. Genes Dev. 11:179-186. https://doi.org/10.1101/gad.11.2.179.

Lodish, H. F., B. Zhou, G. Liu, and C. Z. Chen. 2008. Micromanagement of the immune system by microRNAs. Nat. Rev. Immunol. 8:120-130. https://doi.org/10.1038/nri2252.

Lora, I., A. Barberio, B. Contiero, P. Paparella, L. Bonfanti, M. Brscic A. L. Stefani, and F. Gottardo. 2018. Factors associated with passive immunity transfer in dairy calves: Combined effect of delivery time, amount and quality of the first colostrum meal. Animal 12:1041-1049. https://doi.org/10.1017/S1751731117002579.

Mathivanan, S., H. Ji, and R. J. Simpson. 2010. Exosomes: Extracellular organelles important in intercellular communication. J. Proteomics 73:1907-1920. https://doi.org/10.1016/j.jprot.2010.06 .006 .

McGrath, B. A., P. F. Fox, P. L. H. McSweeney, and A. L. Kelly. 2016. Composition and properties of bovine colostrum: A review. Dairy Sci. Technol. 96:133-158. https://doi.org/10.1007/s13594 $-015-0258-\mathrm{x}$.

McKenna, L. B., J. Schug, A. Vourekas, J. B. McKenna, N. C. Bramswig, J. R. Friedman, and K. H. Kaestner. 2010. MicroRNAs control intestinal epithelial differentiation, architecture, and barrier function. Gastroenterology 139:1654-1664.e1. https://doi.org/ 10.1053/j.gastro.2010.07.040.

Modepalli, V., A. Kumar, L. A. Hinds, J. A. Sharp, K. R. Nicholas, and C. Lefevre. 2014. Differential temporal expression of milk miRNA during the lactation cycle of the marsupial tammar wallaby (Macropus eugenii). BMC Genomics 15:1012. https://doi.org/ 10.1186/1471-2164-15-1012.

Munch, E. M., R. A. Harris, M. Mohammad, A. L. Benham, S. M. Pejerrey, L. Showalter, M. Hu, C. D. Shope, P. D. Maningat, P. H. Gunaratne, M. Haymond, and K. Aagaard. 2013. Transcriptome profiling of microRNA by Next-Gen deep sequencing reveals known and novel miRNA species in the lipid fraction of human breast milk. PLoS One 8:e50564. https://doi.org/10.1371/journal .pone.0050564.

Muth, D. C., B. H. Powell, Z. Zhao, and K. W. Witwer. 2018. miRNAs in platelet-poor blood plasma and purified RNA are highly stable: 
A confirmatory study. BMC Res. Notes 11:273. https://doi.org/10 .1186/s13104-018-3378-6.

O'Connell, R. M., D. S. Rao, A. A. Chaudhuri, and D. Baltimore. 2010. Physiological and pathological roles for microRNAs in the immune system. Nat. Rev. Immunol. 10:111-122. https://doi.org/ $10.1038 /$ nri2708.

Pigati, L., S. C. Yaddanapudi, R. Iyengar, D. J. Kim, S. A. Hearn, D. Danforth, M. L. Hastings, and D. M. Duelli. 2010. Selective release of microRNA species from normal and malignant mammary epithelial cells. PLoS One 5:e13515. https://doi.org/10.1371/journal .pone. 0013515 .

Playfair, L. 1841. On the changes in composition of the milk of a cow, according to its exercise and food. Memoirs Chem. Soc. London 1:174-190. https://doi.org/10.1039/mp8410100174.

Power, M. L., and J. Schulkin. 2013. Maternal regulation of offspring development in mammals is an ancient adaptation tied to lactation. Appl. Transl. Genom. 2:55-63. https://doi.org/10.1016/j.atg 2013.06.001.

Quigley, J. D. 3rd, and J. J. Drewry. 1998. Nutrient and immunity transfer from cow to calf pre- and postcalving. J. Dairy Sci. 81:2779-2790. https://doi.org/10.3168/jds.S0022-0302(98)75836 -9 .

Raboisson, D., P. Trillat, and C. Cahuzac. 2016. Failure of passive immune transfer in calves: A meta-analysis on the consequences and assessment of the economic impact. PLoS One 11:e0150452. https: //doi.org/10.1371/journal.pone.0150452.

Rani, P., M. Vashisht, N. Golla, S. Shandilya, S. K. Onteru, and D. Singh. 2017. Milk miRNAs encapsulated in exosomes are stable to human digestion and permeable to intestinal barrier in vitro. J. Funct. Foods 34:431-439. https://doi.org/10.1016/j.jff.2017.05 .009.

Reinhart, B. J., F. J. Slack, M. Basson, A. E. Pasquinelli, J. C. Bettinger, A. E. Rougvie, H. R. Horvitz, and G. Ruvkun. 2000. The 21-nucleotide let-7 RNA regulates developmental timing in Caenorhabditis elegans. Nature 403:901-906. https://doi.org/10.1038/ 35002607.

Riffo-Campos, Á. L., I. Riquelme, and P. Brebi-Mieville. 2016. Tools for sequence-based miRNA target prediction: What to choose? Int. J. Mol. Sci. 17:1987. https://doi.org/10.3390/ijms17121987.

Sánchez-Macías, D., I. Moreno-Indias, N. Castro, A. Morales-Delanuez, and A. Arguello. 2014. From goat colostrum to milk: Physical, chemical, and immune evolution from partum to 90 days postpartum. J. Dairy Sci. 97:10-16. https://doi.org/10.3168/jds.2013 -6811 .

Seegers, H., C. Fourichon, and F. Beaudeau. 2003. Production effects related to mastitis and mastitis economics in dairy cattle herds. Vet. Res. 34:475-491. https://doi.org/10.1051/vetres:2003027.

Silveri, L., G. Tilly, J. L. Vilotte, and F. Le Provost. 2006. MicroRNA involvement in mammary gland development and breast cancer. Reprod. Nutr. Dev. 46:549-556. https://doi.org/10.1051/rnd: 2006026.

Snow, J. W., A. E. Hale, S. K. Isaacs, A. L. Baggish, and S. Y. Chan. 2013. Ineffective delivery of diet-derived microRNAs to recipient animal organisms. RNA Biol. 10:1107-1116. https://doi.org/10 $.4161 /$ rna.24909.

Soberon, F., E. Raffrenato, R. W. Everett, and M. E. Van Amburgh. 2012. Preweaning milk replacer intake and effects on long-term productivity of dairy calves. J. Dairy Sci. 95:783-793. https://doi .org/10.3168/jds.2011-4391.

Sun, J., K. Aswath, S. G. Schroeder, J. D. Lippolis, T. A. Reinhardt, and T. S. Sonstegard. 2015. MicroRNA expression profiles of bovine milk exosomes in response to Staphylococcus aureus infection. BMC Genomics 16:806. https://doi.org/10.1186/s12864-015-2044 -9 .

Sun, Q., X. Chen, J. Yu, K. Zen, C. Y. Zhang, and L. Li. 2013. Immune modulatory function of abundant immune-related microRNAs in microvesicles from bovine colostrum. Protein Cell 4:197210. https://doi.org/10.1007/s13238-013-2119-9.
Sutton, J. D. 1989. Altering milk composition by feeding. J. Dairy Sci. 72:2801-2814. https://doi.org/10.3168/jds.S0022-0302(89)79426 -1 .

Turchinovich, A., L. Weiz, A. Langheinz, and B. Burwinkel. 2011. Characterization of extracellular circulating microRNA. Nucleic Acids Res. 39:7223-7233. https://doi.org/10.1093/nar/gkr254.

van Dommelen, S. M., P. Vader, S. Lakhal, S. A. Kooijmans, W. W. van Solinge, M. J. Wood, and R. M. Schiffelers. 2012. Microvesicles and exosomes: Opportunities for cell-derived membrane vesicles in drug delivery. J. Control. Release 161:635-644. https://doi.org/10 .1016/j.jconrel.2011.11.021.

Vasseur, E., F. Borderas, R. I. Cue, D. Lefebvre, D. Pellerin, J. Rushen, K. M. Wade, and A. M. de Passille. 2010. A survey of dairy calf management practices in Canada that affect animal welfare. J. Dairy Sci. 93:1307-1315. https://doi.org/10.3168/jds.2009-2429.

Wang, M., S. Moisa, M. J. Khan, J. Wang, D. Bu, and J. J. Loor. 2012. MicroRNA expression patterns in the bovine mammary gland are affected by stage of lactation. J. Dairy Sci. 95:6529-6535. https:// doi.org/10.3168/jds.2012-5748.

Weber, J. A., D. H. Baxter, S. Zhang, D. Y. Huang, K. H. Huang, M. J. Lee, D. J. Galas, and K. Wang. 2010. The microRNA spectrum in 12 body fluids. Clin. Chem. 56:1733-1741. https://doi.org/10 .1373/clinchem.2010.147405.

Wicik, Z., M. Gajewska, A. Majewska, D. Walkiewicz, E. Osinska, and T. Motyl. 2016. Characterization of microRNA profile in mammary tissue of dairy and beef breed heifers. J. Anim. Breed. Genet. 133:31-42. https://doi.org/10.1111/jbg.12172.

Wolf, T., S. R. Baier, and J. Zempleni. 2015. The intestinal transport of bovine milk exosomes is mediated by endocytosis in human colon carcinoma Caco-2 cells and rat small intestinal IEC-6 cells. J. Nutr. 145:2201-2206. https://doi.org/10.3945/jn.115.218586.

Xiao, C., and K. Rajewsky. 2009. MicroRNA control in the immune system: Basic principles. Cell 136:26-36. https://doi.org/10.1016/ j.cell.2008.12.027.

Yang, J., L. M. Farmer, A. A. Agyekum, I. Elbaz-Younes, and K. D. Hirschi. 2015a. Detection of an abundant plant-based small RNA in healthy consumers. PLoS One 10:e0137516. https://doi.org/10 .1371/journal.pone.0137516.

Yang, J., L. M. Farmer, A. A. Agyekum, and K. D. Hirschi. 2015b. Detection of dietary plant-based small RNAs in animals. Cell Res. 25:517-520. https://doi.org/10.1038/cr.2015.26.

Yi, R., Y. Qin, I. G. Macara, and B. R. Cullen. 2003. Exportin-5 mediates the nuclear export of pre-microRNAs and short hairpin RNAs. Genes Dev. 17:3011-3016. https://doi.org/10.1101/gad .1158803 .

Zempleni, J., S. R. Baier, K. M. Howard, and J. Cui. 2015. Gene regulation by dietary microRNAs. Can. J. Physiol. Pharmacol. 93:1097-1102. https://doi.org/10.1139/cjpp-2014-0392.

Zhang, C., Y. Zhao, Y. Wang, H. Wu, X. Fang, and H. Chen. 2014. Deep RNA sequencing reveals that microRNAs play a key role in lactation in rats. J. Nutr. 144:1142-1149. https://doi.org/10.3945/ jn.114.192575.

Zhang, J., F. Zhang, X. Didelot, K. D. Bruce, F. R. Cagampang, M. Vatish, M. Hanson, H. Lehnert, A. Ceriello, and C. D. Byrne. 2009. Maternal high fat diet during pregnancy and lactation alters hepatic expression of insulin like growth factor-2 and key microRNAs in the adult offspring. BMC Genomics 10:478. https://doi .org/10.1186/1471-2164-10-478.

Zhang, L., D. Hou, X. Chen, D. Li, L. Zhu, Y. Zhang, J. Li, Z. Bian, X. Liang, X. Cai, Y. Yin, C. Wang, T. Zhang, D. Zhu, D. Zhang, J. Xu, Q. Chen, Y. Ba, J. Liu, Q. Wang, J. Chen, J. Wang, M. Wang, Q. Zhang, J. Zhang, K. Zen, and C. Y. Zhang. 2012. Exogenous plant MIR168a specifically targets mammalian LDLRAP1: Evidence of cross-kingdom regulation by microRNA. Cell Res. 22:107-126. https://doi.org/10.1038/cr.2011.158. 